\title{
(In)effective Thesis Writing and Supervision: (Lost) Opportunity for Learning
}

\author{
Madhu Neupane Bastola \\ Tribhuvan University, Nepal \\ madhukneupane@gmail.com \\ Bal Mukunda Bhandari \\ Tribhuvan University, Nepal \\ bhandaribm@gmail.com
}

\section{Abstract}

Thesis writing requires a wide range of reading, the skill of critiquing, a good skill of academic writing, and a proper collaboration of student and supervisor; however, it is poorly understood, less explored, and replete with problems. In this paper, we present the merits of thesis writing, supervisors' and students' commonly held perceptions, the effectiveness of supervisory feedback, and the value of student engagement. Then we present two components of thesis writing (i.e., introduction and literature review, including theoretical framework). Considering the need of the novice researchers (i.e., master's students) who are writing their thesis for the first time, we present these two components' introduction and provide suggestions for supervisors. We also present commonly used language features and examples. This paper is expected to be beneficial to students and supervisors alike.

Keywords: thesis writing, supervisors' and students' perceptions, effectiveness of feedback, student engagement

\section{Introduction}

Thesis (or dissertation) writing is an opportunity for students to develop their academic skills, apply knowledge from taught courses, and establish researchpractice nexus. A master's thesis is the climax of a master's degree or a microcosm of the master's degree itself (Hammond, 2019). For many students, it is the first piece of independent research work that demands them to be proactive researchers and, to some extent, contribute to the body of knowledge by means of creative originality (Paltridge \& Starfield, 2019). Sinkovics, Richardson, and Lew (2015), for example, revealed that the thesis writing was an "effective approach for supporting the development of competencies and enhancing employability than narrowly framed taught courses" (p. 310). Their study also reported that thesis writing enabled students "to develop their self-efficacy, improve their emotional regulation, and put aside short-term rewards for long-term goals" 
(p. 311). Moreover, a thesis writing is a key means to disciplinary learning and research training that can prepare students for higher research degrees like MPhil and PhD (Hasrati \& Tavakoli, 2019). Therefore, Hasrati and Tavakoli (2019) argue that not providing master's students with an opportunity to write a thesis is a 'hierarchical symbolic violence' because it deprives them of disciplinary knowledge and academic literacy.

Supervisory feedback is at the heart of postgraduate research supervision (Bitchener, Basturkmen, \& East, 2010; East, Bitchener, \& Basturkmen, 2012). It is worth noting that "feedback would affect the enactment of student agency in their dissertation research" (Yang, Li, Zhou, \& Li, 2020, p. 305). As supervisors have acquired an intimate knowledge of their disciplinary culture, they can draw on their accumulated academic experience and insiders' perspective to guide their students. Their feedback plays a crucial role in socializing students into disciplinary discourse ( $\mathrm{Li}, \mathrm{Hyland}, \& \mathrm{Hu}, 2017$ ) because it is "tailored to the specific needs of students at the point when they are most likely to benefit from it" (Bitchener, 2017b, p. 90). However, to what extent supervisory feedback can achieve its objectives depends on whether it can address students' needs and challenges. Extant research shows that "there is often a gap between what supervisors perceive as useful feedback and what students need" (Kumar \& Stracke, 2017, p. 17). Consequently, "[w] hat the student wants to receive by way of feedback may sometimes differ from what the supervisor gives" (East et al., 2012, p. 1).

Writing a thesis is often a demanding task for students irrespective of their language background (Basturkmen, East, \& Bitchener, 2014; de Kleijn, Meijer, Pilot, \& Brekelmans, 2014). However, English as a second or foreign language (ESL/EFL) students often experience additional difficulties and might require more supervisory support to develop discipline-specific writing competence and practices (Paltridge \& Starfield, 2019; Zheng, Yu, Wang, \& Zhang, 2019). However, despite the rising numbers of students writing a thesis, the supervision is yet to receive sufficient research attention (Neupane Bastola \& Hu, 2021).

Supervision of thesis needs attention for various reasons (Harwood \&Petrić, 2017). First, the thesis supervision phenomenon is occluded, opaque, and poorly understood because supervisors' and students' activities are rarely scrutinized. Although good supervision can be a transformative experience to both supervisors and students, there is little exploration of what makes supervision effective. Second, there are many cases where supervision practices go wrong with "dissatisfaction, dismay, miscommunication - or downright 
supervisory abuse" (Harwood \& Petrić, 2017, p. 35). Third, there can be a lack of understanding regarding supervisors' and students' roles and expectations (Grant, 2010; Paltridge \& Starfield, 2019). Previous research has reported marked differences in supervisors' and students' expectations (East et al., 2012; Kumar \& Stracke, 2007; Paltridge \& Starfield, 2019). Although it is not always the case, new supervisors may be more confused than experienced ones regarding supervision (Amundsen \& McAlpine, 2011). Therefore, "learning more about these expectations, disseminating them, and then seeking to reconcile them would seem a sensible way to ensure better experiences and lessen cases of noncompletion" (Harwood \& Petrić, 2017, p. 46). This paper is an attempt towards this end.

\section{Supervisors' and Students' Perceptions of Thesis Supervision}

People's perceptions of certain phenomena can significantly influence their practices. In the case of supervisory feedback, such perceptions include seeing feedback as social practices, understanding of shared responsibilities, and supervisors' practices of constructing feedback and students' subsequent actions (Vattøy \& Smith, 2019). Extant research (e.g., Carless, 2006; MacKay, Hughes, Marzetti, Lent, \& Rhind, 2019) revealed that students were usually dissatisfied with the feedback they received. For example, an examination of free-text comments of the National Student Survey at a large Scottish Russell Group university (MacKay et al., 2019) revealed that students felt frustrated and alienated because of perceived inadequate support from and limited contact opportunities with academic staff, 'unfair' and non-transparent assessment requirements, and different sets of rules for staff and students. Some students complained that they received a penalty for delayed submission of their assignment, whereas no such penalty was incurred by staff who delayed feedback. The students did not value the feedback that they could not use. It is worth noting that students appreciated it when they received care and support from teachers. Three large-scale questionnaire surveys (de Kleijn, Mainhard, Meijer, Pilot, \& Brekelmans, 2012; de Kleijn et al., 2013; de Kleijn et al., 2014) examining the students' perceptions of different aspects of supervisory feedback at a large Dutch university underscored the importance of positive supervisory support to students' satisfaction and learning. De Kleijn et al.'s (2012) online questionnaire survey found that students who received positive personal support (i.e., affiliation) from their supervisors received higher final grades, were more satisfied, and perceived better supervisory contributions to their learning. Supervisory control (i.e., greater supervisor influence on students' activities) also had a positive linear effect on perceived supervisors' contribution to learning, 
although it had a quadratic effect (i.e., initial positive effect turning to negative when the control increased) on satisfaction and final grades. In another online survey (i.e., de Kleijn et al., 2013), the students reported that positive supervisory feedback informed them of their progress and provided them with sufficient instruction for improvement of their learning. Consistent with previous studies (de Kleijn et al., 2012; de Kleijn et al., 2013), de Kleijn et al. (2014) showed that supervisory support was the strongest predictor for student satisfaction and perceived supervisor contributions to learning.

Research has it that supervisors and students have different expectations and assumptions about feedback practices. For example, Strauss' (2012) exploratory study of the supervision practices of an experienced female supervisor and two of her master's students at a New Zealand university revealed a highly distressing situation in which the supervisor's and the students' diametrically different expectations led them to consider supervision and thesis writing a burden. The supervisor expected the students to be independent and self-regulated in their research, felt frustrated by their poor English and lack of initiatives, and refused to engage with their work until it was finalized. In contrast, the students appeared to be highly dependent and expected clear guidance and hands-on support in every stage of their thesis writing. Consequently, the students saw themselves deficient, experienced plummeting self-esteem and agency, and felt ashamed and useless, although they managed to complete their thesis with the help of Strauss, who was their academic advisor.

Similar differences exist in academic staff's and students' perceptions of student engagement (Lam, 2017). Previous research demonstrated while supervisors found students less serious and engaged with thesis writing (Neupane Bastola, 2020a), students complained of not receiving enough support and guidance (Neupane Bastola, 2020b; Neupane Bastola \& Hu, 2020). Students expected their supervisors to provide them with enough guidance to improve their work; adequate time for consultation meetings, motivation encouragement and empowerment; supervisory relationship underpinned by mutual trust and respect; and support for locating relevant resources (Neupane Bastola, 2020c). Previous research (Mulliner \& Tucker, 2017) has demonstrated that contrary to feedback providers' generally held beliefs, "most students always access, read, and act on feedback and academic staff should not assume that they do not" (p. 2017). In this context, it is relevant to quote Harks, Rakoczy, Hattie, Besser, and Klieme (2014) at some length because their views shed light on differing perceptions: 
Generally, teachers, feedback designers, and researchers assume that students automatically perceive feedback in the way they intended it to be perceived and expect that the information contained in the feedback is unproblematically taken as input into the information-processing, motivational, or self-regulation systems. Relatively little is known about how students perceive feedback and even less about the immediate influence of this perception on further learning processes. (p. 272)

Therefore, it is necessary to take students' perspectives into consideration while providing feedback.

\section{Effectiveness of Supervisory Feedback}

Carless, Salter, Yang, and Lam (2011) argue that feedback is useful, meaningful and sustainable if it can enhance students' autonomy, self-regulation, independence, and zeal for lifelong learning, making the feedback provider redundant in the long run. Such sustainable feedback should pose stimulating questions to students rather than provide answers, engage them in dialogue with peers and teachers, and encourage them to use technology. Consistent with this view, Henderson, Ajjawi, Boud, and Molloy (2019) posit that quality feedback should bring about a changed state in a student, and the "nature of that change could be related to their thinking processes, emotions, relationships, work strategies, identity and more" (p. 26). A large and growing body of research has shown that students appreciate quality feedback is process-oriented, involves students in dialogues, provides judgements of the standard reached, and offers instruction for improvement on learning (Hyland, 2019).

It is worth noting that students might have varying needs for feedback. For example, as reported in existing research, students with lower self-confidence and academic competence desired for directive and specific feedback, whereas those with determination, self-confidence, and stronger academic competence expected guidance (Wang \& Li, 2011). Students might benefit if there is an opportunity to receive feedback from other faculties and their colleagues, (Dysthe, Samara, \& Westrheim, 2006). Although there is a consistent call to expand supervision practices from supervisor-student dyad to the community (Strauss, 2012), this is still a distant reality in our context. What we can do is make supervisors and students aware of their roles and responsibilities and offer multiple avenues of support to cater to their needs (Nicol \& Cornelius, 2018). Such support may include offering courses to develop students' critical thinking as well as academic reading and writing skills, providing exemplars and supportive 
materials, engaging students in workshops, and mentoring new supervisors. Even when such supports are available, the role of close feedback cannot be overemphasized because "most of the real work of research training is done in the dissertation itself" (Maunder, Gordon-Finlayson, Callaghan, \& Roberts, 2012, p.31).

As suggested by Beddoe and Maidment (2017), students might benefit from an explicitly planned and stage-wise directive feedback approach involving three main features: "a writing focus from the beginning, prescriptive feedback, and support that encourages the development of an academic voice" (p. 120). First, the writing focus feedback involves setting expectations for the quality and quantity of writing and encouraging students to write from the beginning, agreeing on the ways of giving and receiving feedback, and helping them make methodological decisions in compliance with research ethics. Second, prescriptive feedback has to do with rewriting a small portion of students' work to set an exemplar for them to follow, setting ground rules (e.g., the amount of writing to be produced for each meeting, and time to return students' work with feedback), ensuring the adoption of the prescribed format and referencing styles, and helping students avoid procrastination. Third, with respect to developing students' academic voices, it is necessary to provide constructive and directive feedback.

A growing body of research on quality supervisory feedback stresses the need to adapt feedback to students' needs and expectations, such as providing more directive feedback for less well-performing and more high-level feedback for aspiring students (Katikireddi \& Reilly, 2017). From this perspective, as Pilcher (2011) argues, quality feedback is an elusive concept because it may mean different things to different people. However, the same elusiveness allows supervisors to adapt feedback to students' diverse needs and expectations. In de Kleijn, Bronkhorst, Meijer, Pilot, and Brekelmans' (2016) qualitative study, 12 Dutch supervisors, with the reputation of being successful, reported having the same goals (i.e., learning and progress) for all the students irrespective of their capabilities. They actively explored students' needs and expectations and adjusted the level of support, the amount of directive and explicit feedback, and the severity of critical comments as required. However, holding up the same standard for all the students required 'too much supervisory support' in the case of students not well-prepared for thesis writing. Subsequent research has consistently reported successful supervisors' preference for adaptive supervision (Harwood \& Petrić, 2020). A recent longitudinal case study (Harwood \& Petrić, 2020) involving an experienced and successful supervisor and an academically strong student at a UK university also demonstrated the benefits of flexible 
supervision adapted to students' diverse needs and capabilities (i.e., a studentsensitive partnership model). The supervisor reported that he would vary the style of supervision as required by different students or by the same student at different stages of the research process. Unlike supervisors in previous studies (e.g., de Kleijn et al., 2016), this supervisor managed to strike a balance in the amount and strictness of supervision provided, as required. He welcomed his student to regulate the supervisor-student meetings but chased him when necessary. The student appreciated this flexible approach because it allowed him the freedom to work on his own and receive support whenever he needed it.

\section{Student Engagement}

Recent scholarship informed by a sociocultural perspective characterizes learning as a student-centered, long-term, dynamic, and dialogic process. According to Wisker (2012), in the case of thesis supervision, feedback dialogue can take place "face-to-face or through electronic/postal/textual means" (p. 187). The conceptualization of feedback as a dialogic process places such a high premium on student engagement that "without student action, we cannot meaningfully use the term feedback" (Henderson et al., 2019, p. 4). From this perspective, highly informative and constructive feedback remains useless without student agency and engagement. It is important to note that engagement is a multidimensional construct involving affective, behavioural, and cognitive aspects (Fredricks, Blumenfeld, \& Paris, 2004). Affective engagement might influence students' willingness to enact supervisory feedback (Fredricks et al., 2004, p. 60). It involves both positive (i.e., motivation, interest) and negative (i.e., boredom, sadness, anxiety) emotions associated with feedback. Such emotions mostly hinge upon the types of comments that students receive. For example, positive comments may provide students with a sense of support, encouragement, and the incentive to act on feedback. In contrast, negative and upsetting comments can damage students' self-confidence (Henderson et al., 2019). In extreme cases, negative feedback may even lead to failure and eventual drop-out (Tai, Dawson, Bearman, \& Ajjawi, 2019). Behavioural engagement refers to students' involvement and participation in desirable academic activities leading to a successful outcome. It includes "effort, intensity, persistence, determination, and perseverance in the face of obstacles and difficulties" (Skinner \& Pitzer, 2012 , p. 24). It is worth noting that behaviourally engaged students tend to elicit better academic support (Skinner \& Pitzer, 2012). Supervisors "want students to engage with their feedback, not just because they have invested time and energy in providing it, but because they believe this engagement is crucial for students' development" (Han \& Hyland, 2019, p. 247). Cognitive engagement 
involves students" “investment in deep learning, self-regulation, perceived future relevance of learning, thoughtfulness, and willingness to exert necessary efforts" (Neupane Bastola, 2020a, p. 3). According to Skinner and Pitzer (2012), cognitive engagement "encompasses attention, concentration, focus, absorption, 'headson' participation, and a willingness to go beyond what is required" (p. 24). The foregoing discussion shows that for thesis supervision to be effective, there should be synergy between supervisors' and students' expectations, perspectives, and support/engagement. Therefore, it is crucial to understand thesis writing as a collaborative work between supervisor and student.

In this paper, we will provide guidelines for prospective students and supervisors regarding two components of thesis writing that is, introduction and literature review including theoretical framework.

\section{Writing Introduction}

The introduction is the most important part of a thesis. It flows from general to specific. The main purpose of the introduction chapter is to set the context for the study and provide background information to orient the readers to the research topic. In this section, "the writer makes claims for the centrality or significance of the research in question and begins to outline the overall argument of the thesis" (Paltridge \& Starfield, 2007, p. 85) in order to show "the relevance of the research about to be reported in the thesis to previous work in the field" (Bunton, 2002, p. 58). To make a strong case for research, the chapter should "appropriately situate the work within the existing body of related research and attempt to attract an audience" (Swales \& Feak, 2012, p. 328).

In this regard, the introduction section should serve three main functions: establishing a research territory, establishing a niche (i.e., research gap), occupying the niche (i.e., the rationale for the research) (Biggam, 2017; Swales \& Feak, 2012). Establishing territory means setting the context of the research. It can be done by giving some background information and stating why the area we have chosen for research is essential, relevant, or useful. This information should be based on our reading of literature. Generally, novice researchers tend to provide copious background information loosely related to the research in question. It is worth noting that the background information should be directly relevant to the research.

Second, the introduction section should provide the gap existing in the existing knowledge base. In other words, it should tell the readers what is lacking in 
our understanding of the phenomena that we want to investigate. One of the main purposes of research is to add to the body of knowledge and generate new insights. Therefore, it is necessary to read previous research to identify what knowledge is lacking. This does not mean that each research should be 'brand new'. The gaps can be identified in terms of context, methodology, or theoretical perspectives. In a thesis, gaps are generally discussed under the heading 'statement of the (research) problem'.

Third, the introduction section sets the purpose and significance of the research as well as indicates the structure of the paper. This can be done by outlining the purpose of research, listing questions to be answered, defining key term operationally (i.e., the sense in which the terms are used in the thesis), and indicating the theoretical framework and methodology employed to answer the research questions raised in the study. The final section of the introduction chapter should present the organization of the thesis. It is worth noting that these three functions occur cyclically in the introduction chapter(Bunton, 2002).

Suggestions for students. First, the students need to learn about the area they want to investigate and find out why the area needs research. Therefore, to gain more information about the research area, they can consult various sources like books, journals, newspapers, magazines, and conference proceedings. They can start exploring the area even when they have only a vague idea of what they want to do. For example, if the focus of the research is on student engagement, they can read more about meaning and types of engagement, activities that promote or hinder engagement, the relationship between student engagement and academic achievement, previous research and their findings, and suggestions for further research. Research is not about knowing everything in advance and writing down the information in the paper. It is about searching for information and being clear in the process. We would like to emphasize what Biggam (2017) has to say, "Ideas for dissertation focus will not appear out of thin air: you need to do some basic groundwork" (p. 32). Students commonly come to supervisors to say, "I cannot find anything on my topic," without doing even fundamental searches. It is essential to be clear that they are the primary agent of thesis writing activity and they are writing a thesis not only for 'getting through' a degree but for learning. Therefore, it is crucial to be responsible and independent as far as possible. The more they are engaged, the better support they are likely to receive. Newton's third law of motion applies in thesis writing as well! Once they have enough information, the student can start writing background. 
Suggestions for supervisors. Supervisors need to see thesis writing from students' perspective. The things that appear to be very clear to supervisors might be utterly new to students. Just going back to their own experience of writing their first thesis should make supervisors empathetic to students' challenges and struggles. When the students are at the beginning stage of their thesis, it is very important to guide them to some focused reading materials such as a couple of books and three/four research articles in their area. It may be necessary to discuss these materials with students. These key readings help students engage in productive reading. These materials also work as exemplars and help students learn salient features of writing (Smyth \& Carless, 2020). In writing, these exemplars help students generate internal feedback by comparing their writing with the materials they are reading. The first author of this paper recalls that when she submitted her first draft of her M.Ed. TESOL thesis to her supervisor at the University of Sydney, the supervisor sent his articles and asked her to read the methodology section. That helped her immensely. Since then, she usually makes use of exemplars while writing. If selected appropriately, such exemplars can be a significant input source to students to generate inner feedback. When students are writing the introduction section, supervisors should guide students to read the introduction section of previous theses and research articles with focused attention to various aspects, structure, and language features. It is necessary to encourage students and appreciate their small efforts with patience, care, and clear guidance on the various aspects of introduction section. For example, the supervisors can help the students write a statement of the problem by discussing the research questions they plan to investigate. Such a discussion "helps students to sharpen their understanding of the focus of the problem that informs the various research questions" (Bitchener, 2017a, p. 92). In writing the significance of the study, students can also be encouraged to "think about whether there are any personal circumstances that led them to an interest in the field of study" (Bitchener, 2017a, p. 95).

Language of introduction. There are some specific linguistic features that are used to realize different moves (i.e., functions). The present perfect tense is commonly used to present the significance of the research area. Different adjectives can also be used to underscore the significance of the research in question. Some examples are presented below:

Move 1: Establishing a research territory (background)

1. These potential benefits notwithstanding, doctoral students seeking to publish during candidature tend to face myriad difficulties, ranging from 
ways of writing to ways of knowing and ways of being. (Lei \& Hu, 2019, p. 63)

2. In recent years, there has been a renewed focus on feedback practices in higher and professional education to identify what they are, how they can be conceptualized and how they can be more effectively deployed. ( Ajjawi \& Boud, 2017, p. 251)

3. Concomitantly, institutions are realising the need to identify postgraduate students' research writing needs and provide effective pedagogy to support them in the development of scholarly writing (Basturkmen, East, \& Bitchener, 2014, p. 433 )

4. A number of influential meta-analyses have confirmed that feedback is central to student learning. (Carless, 2006, p. 219)

Move 2: Identifying niche (statement of problem/research gaps)

The language of this move is evaluative nature. Present tense is commonly used.

5. Although this research has shed much light on doctoral students' scholarly publishing activities, another useful theoretical lens through which to examine and understand such activities is Activity Theory. (Lei \& Hu, 2019, p. 63)

6. Despite its central impact on learning, feedback is still relatively underexplored (Higgins et al., 2002), and is a process which faces challenges, such as time, miscommunication and emotional barriers. (Carless, 2006, p. 220)

Move 3: Occupying the niche (significance/rationale/motivation)

7. As will be elucidated in the findings, Activity Theory and its notions of primary and secondary contradictions can shed light on not only the structural tensions underlying the difficulties doctoral students face in their scholarly publishing activities, but also the learning opportunities entailed therein (Lei \& Hu, 2019, p. 64).

8. This paper aims to contribute to the literature on supervision. (Basturkmen et al., 2014, p. 433)

9. The value of the article lies in exemplifying the different perceptions of students and tutors with regard to the assessment and feedback process (Carless, 2006, p. 220) 


\section{Writing a Literature Review}

The literature review is one of the most crucial parts of thesis writing. In a general sense, it is a written summary of previous research and provides us with the knowledge of the current state of knowledge in our research interest. It provides a sound base for new research. As mentioned in the previous section, we cannot identify research gaps and justify the need for our research without reviewing the literature. It is an excellent opportunity to learn from other scholar's ideas and work. To be more specific, the main purposes of the literature review are to set the context for research, identify research gaps, understand theoretical framework and methods that inform the research, justify the research, and refine research questions.

The term 'theoretical framework' may appear complex to novice researchers because it sounds too abstract to grasp. Students also find it confusing to distinguish between the terms 'theoretical framework' and 'conceptual framework'. According to Casanave and Li (2015), these two terms can be used interchangeably, with the latter being more concrete than the former. A theory helps us "explain or justify why and how the study is being done, lets readers know what the study is and is not about and helps researchers support and interpret findings and connect them to other" (Casanave \& Li, 2015, p. 107). It makes the relationship between concepts clear and frames the study. A theory is necessary for a higher level of interpretation or conceptualization going beyond the concrete data. It helps researchers to gain new insights to make sense of the data. Although the literature review forms the second chapter of the thesis, the conception of research usually begins with a review of the literature, and the process continues until the research is complete.

Suggestions for students. The common problems students might face while writing a literature review are of four types: locating literature, citing and referencing literature properly, reviewing the literature, and organizing literature review chapter (Biggam, 2017; Paltridge \& Starfield, 2019).

Locating the relevant literature. Relevant literature can be located by searching the work of key authors in the research area. After finding some key resources, students can follow their reference lists to find other related studies. They can also browse the internet (e.g., Google scholar) or visit the library for locating the resources. As Biggam (2017) notes: 
The material you need will not appear all at once; rather, you will discover that one source will lead to another, one author directing you to another, one article referring to another article that may be of use to you, and so on. Collecting literature sources is an accumulative process that requires patience and perseverance in equal measure. (p. 53)

It is necessary to focus on a variety of sources and avoid using uncritical web resources.

Citing and referencing. Citing and referencing are very crucial skills in academic writing. It is common for students to overlook the need to compile the sources during reviewing and panic at the end. This citing and referencing task can be done more efficiently by using reference management software like Zotero (https://www.zotero.org/). There are many styles of referencing, and it is necessary to follow the prescribed format consistently. It is not necessary to memorize the style by heart but be careful and consult the prescribed referencing manuals (e.g., APA, MLA) whenever in confusion. Irrespective of the style of referencing, there three are ways of citing sources: (a) central (strong author focus), (b) non-central (weak author focus), and (c) non-reporting (no specific focus to the author) (Paltridge \& Starfiled, 2019):

1. Central reporting: Basturkmen et al. (2014) found that comments on linguistic accuracy and appropriateness far outnumbered those on content, requirements, and cohesion/coherence.

2. Non-central reporting: A similar case study at a Macau University (Zheng et al., 2019) revealed that the feedback focused on content and language.

3. Non-reporting: Praise may boost students' confidence and foster their selfesteem (Hyland \& Hyland, 2001).

If there is an error in the source of the quoted material, quote as it is and "place sic in square brackets (i.e. [sic]) to indicate that you are aware of the error and it is not your error" (Biggam, 2017, p. 60).

Critical reading of literature. Another crucial aspect of the literature review is critical reading. This is a challenging part not only for novice but also for seasoned researchers. Critical reading is necessary to identify positive aspects (e.g. research area, methodology, theoretical perspective, and finding) and weaknesses (under-researched issues, vague concepts, inappropriate methodology, contended or unconvincing results). Usually, weaknesses of 
previous studies can also be found under the section 'limitations of the study'. Such critical reading helps us to make our research more rigorous. However, it is worth noting that "you do not need to evaluate critically every piece of literature that you read or interpret and assess the worth of every quotation that you use" (Biggam, 2017, p. 68). Try to use a critical lens whenever appropriate. Reading and rereading and writing and rewriting are the keys to any writing and even more so for writing a literature review. While reviewing each resource, it is necessary to take note of the information to answer the key questions like the following:

\section{Who carried out the research?}

2. Who were the participants involved in the research?

3. What were the objectives/research questions/hypotheses?

4. Where was it carried out?

5. What methodology was employed? Was the methodology appropriate to answer the questions raised in the study?

6. When was the research published?

7. How were the data analyzed? Qualitatively, quantitatively or both?

8. What were the findings of the research? How do the findings relate to other studies? Are the findings similar or different from other studies?

9. Are the findings convincing and plausible?

Structuring literature review. The organization of literature review usually follows the order of research questions. This section should cover main variables, concepts, themes, and theories. It usually culminates in the implication of review to the research. These main variables and concepts are "referred to and woven throughout the rest of the dissertation or thesis" (Wisker, 2012, p. 434). Therefore, anything that is not directly relevant to the research questions or objectives should not be included in the review. For novice researchers, it is very easy to drift away from "research objectives to find themselves immersed in writing about peripheral aspects of their topic that are extraneous to their research" (Biggam, 2017, p. 51). 
Suggestions for supervisors. The literature review is "typically regarded as the most difficult chapter for students to write, not only because it serves a variety of purposes and spans a large amount of text but also because it draws upon a wide range of reading, thinking and writing skills, not to mention a critical stance with regard to the literature that is presented" (Bitchener, 2017, p.96). Therefore, students need greater scaffolding and handholding from supervisors. The feedback on literature should mainly focus on two key aspects: the selection of content and critical reading of literature. Supervisors need to support students in the selection of content. Their "extensive knowledge of the field certainly helps them to guide their students regarding relevance and coverage of the content" (Bitchener, 2017, p.98). It is equally important to guide students to locate relevant literature. As we mentioned earlier, providing students with some key readings, and teaching them skills to explore further resources might be helpful. Students need handholding in critical reading of literature. For novice researchers like graduate students, there is a temptation to accept everything in the print as truth. Therefore, feedback aiming to promote 'critical reading of empirical literature, according to Bitchener (2017) should focus on "(1) asking students to what extent the conclusions that based on the findings that have been reported and (2) on whether a sound and robust research methodology inform the findings" (p. 98). Novice researchers struggle to choose and understand and utilize theoretical framework that informs their research. The following quote from a student, reported in Neupane Bastola (2020c), illustrates a case in point:

I don't have any idea about the theory to support a whole thesis. My supervisor suggested I follow a typical theory or a specific school of thought for my work, which I could not get then until now upon completing my research work. As my work was about multiculturalism, I was not allowed to express my ideas freely. Rather I was suggested to follow a specific culturalist and his/her school of thought, like Homi K. Bhabha or Arjun Appadurai. (p. 66)

Some students might present the theoretical framework that is not relevant to their study, while others might struggle to connect the ideas from the framework to explain and discuss the findings. As Casanave and Lee (2015) suggest, "all scholars, novice and seasoned alike, need to read" (p. 114). Therefore, supervisors should guide students in the targeted reading of theoretical work as well as empirical studies that have applied the theory in question. Students should be encouraged and guided "to note whether and how the authors frame their studies with concepts and theories" (p. 114). It is not necessary that students need to understand 'grand' theories. They should be guided to use some theoretical concepts to frame their research. 
Language of literature review. One of the confusions that students usually have about literature review is the use of tense. Three commonly used tenses in the literature review are simple present, simple past, and present perfect (see Table 1).

\section{Table 1. Use of Tense in the Literature Review}

\begin{tabular}{|l|l|}
\hline Choice of Tense & Reasons \\
\hline Present simple & $\begin{array}{l}\text { A generalization is being made. } \\
\text { A reference is being made to the state of current knowledge. } \\
\text { Previous findings are being presented/are accepted as facts. }\end{array}$ \\
\hline Simple past & $\begin{array}{l}\text { A reference is being made to a single study } \\
\text { A specific piece of research and its findings are being } \\
\text { referred to }\end{array}$ \\
\hline Present perfect & $\begin{array}{l}\text { A general area of investigation or inquiry is being referred to } \\
\text { A general statement is made about previous research }\end{array}$ \\
\hline
\end{tabular}

\section{Conclusion}

Thesis writing offers students an excellent opportunity for meaningful learning. However, whether students benefit from thesis writing depends on how the process goes. If the process goes well, it can be a satisfying experience for both supervisors and students and a transforming experience for students. In many cases, however, it has been a lost learning opportunity for students. Therefore, the students need to be cognizant that they are the ultimate beneficiaries and responsible agents for writing. No amount of institutional support and quality feedback makes sense until students engage with feedback seriously, be proactive in seeking feedback rather than expect ready-made answers and appreciate the value of feedback from supervisors. It is vital to understand that multiple revisions are essential because the only way to learn and refine writing is by writing!

Supervisors should always keep students' best interests at the center while providing feedback. Finally, students' judgments of supervisors' research integrity, credibility, and academic trust influence their engagement with feedback. As Winstone, Nash, Rowntree, and Parker (2017) put it, students "may need to trust the source of feedback before they will be prepared to act on it" (p. 23). Therefore, supervisors should continuously develop their research skills and knowledge 
base to present themselves as models for students. We are working under challenging circumstances. However, challenges, contradictions, and dilemmas will always be there even in seemingly 'perfect' situations. Therefore, it is crucial to reflect on the practices and implement the lesson learned to enhance thesis supervision in the best interest of all the stakeholders (i.e., students, supervisors, and university). We have no options but to start from where we are. If we work responsibly, we can make a difference.

\section{References}

Amundsen, C., \& McAlpine, L. (2011). New academics as supervisors: A steep learning curve with challenges, tensions and pleasures. In L. McAlpine \& C. Amundsen (Eds.), Doctoral education: Research-based strategies for doctoral students, supervisors and administrators (pp. 37-56). Springer Science \& Business Media.

Basturkmen, H., East, M., \& Bitchener, J. (2014). Supervisors' on-script feedback comments on drafts of dissertations: Socialising students into the academic discourse community. Teaching in Higher Education, 19(4), 432-445.

Beddoe, L., \& Maidment, J. (2017). Directive feedback in honors or master's degree research. In S. Carter \& D. Laurs (Eds.), Developing research writing: A handbook for supervisors and advisors (pp. 119-124). London: Routledge.

Biggam, J. (2017). Succeeding with your Master's dissertation: A step-by-step handbook. London: Open University Press.

Bisson, M.-J., van Heuven, W. J. B., Conklin, K., \& Tunney, R. J. (2013). Incidental acquisition of foreign language vocabulary through brief multi-modal exposure. PLOS ONE, 8(4),

Bitchener, J. (2017a). A guide to supervising non-native English writers of theses and dissertations: Focusing on the writing process. London: Routledge.

Bitchener, J. (2017b). Written feedback typically provicded on L2 student's chapter drafts. In S. Carter \& D. Laurs (Eds.), Developing research writing: A handbook for supervisors and advisors (pp. 89-95). London: Routledge.

Bitchener, J., Basturkmen, H., \& East, M. (2010). The focus of supervisor written feedback to thesis/dissertation students. International Journal of English Studies, 10(2), 7997.

Bunton, D. (2002). Generic moves in PhD thesis introductions. In Academic discourse (pp. 57-75). London: Routledge. 
Carless, D. (2006). Differing perceptions in the feedback process. Studies in Higher Education, 31(2), 219-233.

Carless, D., Salter, D., Yang, M., \& Lam, J. (2011). Developing sustainable feedback practices. Studies in Higher Education, 36(4), 395-407.

Casanave, C., \& Li, Y. (2015). Novices' struggles with conceptual and theoretical framing in writing dissertations and papers for publication. Publications, 3(2), 104-119.

de Kleijn, R. A. M., Bronkhorst, L. H., Meijer, P. C., Pilot, A., \& Brekelmans, M. (2016). Understanding the up, back, and forward-component in master's thesis supervision with adaptivity. Studies in Higher Education, 41(8), 1463-1479.

de Kleijn, R. A. M., Mainhard, M. T., Meijer, P. C., Pilot, A., \& Brekelmans, M. (2012). Master's thesis supervision: Relations between perceptions of the supervisorstudent relationship, final grade, perceived supervisor contribution to learning and student satisfaction. Studies in Higher Education, 37(8), 925-939.

de Kleijn, R. A. M., Meijer, P. C., Pilot, A., \& Brekelmans, M. (2014). The relation between feedback perceptions and the supervisor-student relationship in master's thesis projects. Teaching in Higher Education, 19(4), 336-349.

Dysthe, O., Samara, A., \& Westrheim, K. (2006). Multivoiced supervision of Master's students: A case study of alternative supervision practices in higher education. Studies in Higher Education, 31(3), 299-318.

East, M., Bitchener, J., \& Basturkmen, H. (2012). What constitutes effective feedback to postgraduate research students? The students' perspective. Journal of University Teaching \& Learning Practice, 9(2), 1-16.

Fredricks, J. A., Blumenfeld, P. C., \& Paris, A. H. (2004). School engagement: Potential of the concept, state of the evidence. Review of Educational Research, 74(1), 59-109.

Grant, B. M. (2010). Improvising together: The play of dialogue in humanities supervision. Arts and Humanities in Higher Education, 9(3), 271-288.

Hammond, L. (2019). The activity of student research: Using Activity Theory to conceptualise student research for Master's programmes. Studies in Higher Education, 1-13.

Han, Y., \& Hyland, F. (2019). Learner engagement with written feedback: A sociocognitive perspective. In K. Hyland \& F. Hyland (Eds.), Feedback in second language writing (2nd ed., pp. 247-264). Cambridge: Cambridge University Press. 
Harks, B., Rakoczy, K., Hattie, J., Besser, M., \& Klieme, E. (2014). The effects of feedback on achievement, interest and self-evaluation: The role of feedback's perceived usefulness. Educational Psychology, 34(3), 269-290.

Harwood, N., \& Petrić, B. (2017). Experiencing master's supervision: Perspectives of international students and their supervisors. London: Routledge Taylor \& Francis Group.

Harwood, N., \& Petrić, B. (2020). Adaptive master's dissertation supervision: A longitudinal case study. Teaching in Higher Education, 25(1), 68-83.

Hasrati, M., \& Tavakoli, P. (2019). The rise of non-dissertation track master's programmes: An academic literacies approach. Innovations in Education and Teaching International, 56(5), 639-651.

Henderson, M., Ajjawi, R., Boud, D., \& Molloy, E. (2019). Identifying feedback that has impact. In M. Henderson, R. Ajjawi, D. Boud, \& E. Molloy (Eds.), The impact of feedback in higher education (pp. 15-34). Cham: Springer International Publishing.

Hyland, K. (2019). What messages do students take from teacher feedback? In K. Hyland \& F. Hyland (Eds.), Feedback in second language writing (2nd ed., pp. 265-284). Cambridge: Cambridge University Press.

Katikireddi, S. V., \& Reilly, J. (2017). Characteristics of good supervision: A multiperspective qualitative exploration of the Masters in Public Health dissertation. Journal of Public Health, 39(3), 625-632.

Kumar, V., \& Stracke, E. (2007). An analysis of written feedback on a PhD thesis. Teaching in Higher Education, 12(4), 461-470.

Kumar, V., \& Stracke, E. (2017). Settling students into community of practice: In S. Carter \& D. Laurs (Eds.), Developing research writing: A handbook for supervisors and advisors (pp. 17-22). London: Routledge.

Lam, R. (2017). Enacting feedback utilization from a task-specific perspective. The Curriculum Journal, 28(2), 266-282.

Lei, J., \& Hu, G. (2019). Doctoral candidates' dual role as student and expert scholarly writer: An activity theory perspective. English for Specific Purposes, 54, 62-74.

Li, Y., Hyland, F., \& Hu, G. (2017). Prompting MEd students to engage with academia and the professional world through feedback. Journal of English for Academic Purposes, 26, 52-65. 
MacKay, J. R. D., Hughes, K., Marzetti, H., Lent, N., \& Rhind, S. M. (2019). Using National Student Survey (NSS) qualitative data and social identity theory to explore students' experiences of assessment and feedback. Higher Education Pedagogies, 4(1), 315330.

Maunder, R. E., Gordon-Finlayson, A., Callaghan, J., \& Roberts, A. (2012). Behind supervisory doors: Taught master's dissertation students as qualitative apprentices. Psychology Learning \& Teaching, 11(1), 30-38.

Neupane Bastola, M. (2020a). Engagement and challenges in supervisory feedback: Supervisors' and students' perceptions. RELC Journal, 003368822091254.

Neupane Bastola, M. (2020b). Formulation of feedback comments: Insights from supervisory feedback on master's theses. Innovations in Education and Teaching International, 1-10.

Neupane Bastola, M. (2020c). Supervisory feedback: A mixed-methods multi-perspectival study (An unpublished PhD thesis). The Hong Kong Polytechnic University, Hong Kong.

Neupane Bastola, M., \& Hu, G. (2021). Supervisory feedback across disciplines: Does it meet students' expectations? Assessment \& Evaluation in Higher Education, 46(3), 407-423.

Nicol, S., \& Cornelius, S. C. (2018). Effective supervision of master's researchers in professional context. In S. Carter \& D. Laurs (Eds.), Developing research writing: A handbook for supervisors and advisors (pp. 125-132). London: Routledge.

Paltridge, B., \& Starfield, S. (2007). Thesis and dissertation writing in a second language: A handbook for supervisors. London: Routledge.

Paltridge, B., \& Starfield, S. (2019). Thesis and dissertation writing in a second language: A handbook for students and their supervisors (Second Edition). New York: Routledge.

Pilcher, N. (2011). The UK postgraduate Masters dissertation: An 'elusive chameleon'? Teaching in Higher Education, 16(1), 29-40.

Sinkovics, R. R., Richardson, C., \& Lew, Y. K. (2015). Enhancing student competency and employability in international business through master's dissertations. Journal of Teaching in International Business, 26(4), 293-317.

Skinner, E. A., \& Pitzer, J. R. (2012). Developmental dynamics of student engagement, coping, and everyday resilience. In S. L. Christenson, A. L. Reschly, \& C. Wylie (Eds.), Handbook of research on student engagement (pp. 21-44). Boston, MA: Springer US. 
Smyth, P., \& Carless, D. (2020). Theorising how teachers manage the use of exemplars: Towards mediated learning from exemplars. Assessment \& Evaluation in Higher Education, 1-14.

Strauss, P. (2012). 'The English is not the same': Challenges in thesis writing for second language speakers of English. Teaching in Higher Education, 17(3), 283-293.

Swales, J. M., \& Feak, C. B. (2012). Academic writing for graduate students: Essential tasks and skills. Michigan: University of Michigan Press.

Tai, J., Dawson, P., Bearman, M., \& Ajjawi, R. (2019). Beware the simple impact measure: Learning from the parallels with student engagement. In M. Henderson, R. Ajjawi, D. Boud, \& E. Molloy (Eds.), The impact of feedback in higher education (pp. 3750). Cham: Springer International Publishing.

Vattøy, K.-D., \& Smith, K. (2019). Students' perceptions of teachers' feedback practice in teaching English as a foreign language. Teaching and Teacher Education, 85, 260268.

Wang, T., \& Li, L. Y. (2011). 'Tell me what to do' vs. 'guide me through it': Feedback experiences of international doctoral students. Active Learning in Higher Education, 12(2), 101-112.

Winstone, N. E., Nash, R. A., Rowntree, J., \& Parker, M. (2017). 'It'd be useful, but I wouldn't use it': Barriers to university students' feedback seeking and recipience. Studies in Higher Education, 42(11), 2026-2041.

Wisker, G. (2012). The good supervisor: Supervising postgraduate and undergraduate research for doctoral theses and dissertations. Macmillan International Higher Education.

Yang, W., Li, Y., Zhou, W., \& Li, H. (2020). Learning to design research: Students' agency and experiences in a master of education program in Hong Kong. ECNU Review of Education, 3(2), 291-309.

Zheng, Y., Yu, S., Wang, B., \& Zhang, Y. (2019). Exploring student engagement with supervisor feedback on master's thesis: Insights from a case study. Innovations in Education and Teaching International, 1-12. 